\title{
Influence of radial clearance on nonlinear dynamics of a two- span three-support rotor system
}

\author{
HE Xing ${ }^{1}$, WU Yi-ming ${ }^{2}$, LI Mo ${ }^{1 *}$, ZENG Fan ${ }^{1}$ \\ ${ }^{1}$ College of Power Engineering, Naval Univ. of Engineering, Wuhan 430033, China \\ ${ }^{2}$ China state shipbuilding corporation limited 703 Wuxi Branch, Wuxi 214151, China
}

\begin{abstract}
Aiming at the structural form of a certain rotor system, a double-span three-support rotor system model is established. It is supported by three rolling bearings and has a typical nonlinear characteristic. The fourth-order Runge-Kutta method is used to solve the differential equations and analyze the nonlinear dynamic characteristics of the rotor system when the radial clearance of the bearing changed. The research results: with the increase of the rear bearing radial clearance, the rotor system performs single cycle, periodic two and pseudo-periodic motion. With the three location bearing radial clearance increases, the rotor system performs single cycle, periodic two and periodic four motion. When the radial clearance is bigger, the rotor system performs two periodic motion. The influence law of radial clearance on double span three - braced rotor system is shown.
\end{abstract}

\section{The introduction}

The rolling bearing is widely used in the rotor system of ship-used gas turbine, aero-engine and other rotating power machinery. It has the advantages of small kinematic friction coefficient, light weight, easy installation and cooling, etc. The research on the nonlinear dynamic characteristics of the rolling bearing rotor system at home and abroad has made great achievements.

Tiwari $\mathrm{M}$ and Gupta $\mathrm{K}^{[1]}$ studies the nonlinear influence of bearing radial clearance on bearing rotor system, and obtains the influence law of bearing radial clearance on system dynamics. Mevel B et al. ${ }^{[2]}$ establish a two-degree-of-freedom rotor system model of rolling bearing, considered the radial clearance of the bearing, studied the influence of the change of damping on the bifurcation chaos characteristics of the system, and found three ways to chaos. C. Guo et al. ${ }^{[3]}$ establish a dynamic model of rolling bearing rotor system with symmetrical support of three degrees of freedom. H. Bao-chai et al. ${ }^{[4]}$ establish the dynamic model of the single-degree of freedom rotor system. Y. Ru et al. ${ }^{[5]}$ establish the dynamic model of the offset rotor system of the rolling bearing. L. Ming-xuan ${ }^{[6]}, Z$. Chun-jin ${ }^{[7]}$, W. Mei-ling et al. ${ }^{[8]}$ take the Jeffcott rotor as the research object, establish the nonlinear dynamics model of the offset rotor system of rolling bearing, and studies the influence of offset distance and radial clearance of bearing on the nonlinear dynamics of the rotor subsystem.

The previous literature mainly focuses on the simple rotor system model and adopts the same supporting bearing. However, a low-pressure rotor system of a gas turbine is supported by three rolling bearings, namely a ball bearing and two cylindrical rolling bearings, with asymmetric support. Therefore, it is necessary to establish and study a double-span three-support bearing rotor system model.

\section{Dynamic model of double-span three- support rotor.}

\subsection{Nonlinear bearing force model for rolling bearing}

The bearing of the rolling bearing has strong linearity. The radial clearance and nonlinear contact of the rolling bearing should be considered. According to Hertz contact theory, the nonlinear bearing force of the rolling bearing is obtained, and the formula of the nonlinear bearing force of the rolling bearing is obtained. The $k_{b}$ is the nonlinear Hertz contact stiffness.

$\left\{\begin{array}{c}f_{b x}=\sum_{j=1}^{Z} f_{j, x}=\sum_{j=1}^{Z} f_{j} \cos \left(\theta_{j}\right)=k_{b} \sum_{j=1}^{Z} H\left(\chi_{j}\right) \chi_{j}{ }^{n} \cos \left(\theta_{j}\right) \\ f_{b y}=\sum_{j=1}^{Z} f_{j, y}=\sum_{j=1}^{Z} f_{j} \sin \left(\theta_{j}\right)=k_{b} \sum_{j=1}^{Z} H\left(\chi_{j}\right) \chi_{j}{ }^{n} \sin \left(\theta_{j}\right)\end{array}\right.$

Among them

$\theta_{j}=\frac{R_{\mathrm{i}}}{R_{\mathrm{i}}+R_{\mathrm{o}}} t+\frac{2 \pi}{Z}(\mathrm{Z}-j), \quad j=1,2,3 \ldots \ldots Z$

$\chi_{j}=x \cos \theta_{j}+y \sin \theta_{j}-G r$

$H\left(\chi_{j}\right)= \begin{cases}1 & \chi_{j}>0 \\ 0 & \chi_{j} \leq 0\end{cases}$

When the rolling bearing is a ball bearing, $n=3 / 2$; when the rolling bearing is a cylindrical rolling bearing, $n=10 / 9$.

*572029663@qq.com 


$$
\begin{aligned}
& m_{b 1} \ddot{x}_{b 1}+c_{b 1} \dot{x}_{b 1}+k_{1}\left(x_{b 1}-x_{p 1}\right)=-f_{b 1 x} \\
& m_{b 1} \ddot{y}_{b 1}+c_{b 1} \dot{y}_{b 1}+k_{1}\left(y_{b 1}-y_{p 1}\right)=-f_{b 1 y}-m_{b 1} g \\
& m_{p 1} \ddot{x}_{p 1}+c_{p 1} \dot{x}_{p 1}+k_{1}\left(x_{p 1}-x_{b 1}\right)+k_{2}\left(x_{p 1}-x_{p 2}\right)=m_{p 1} e_{1} \omega^{2} \cos (\omega t) \\
& m_{p 1} \ddot{y}_{p 1}+c_{p 1} \dot{y}_{p 1}+k_{1}\left(y_{p 1}-y_{b 1}\right)+k_{2}\left(y_{p 1}-y_{p 2}\right)=m_{p 1} e_{1} \omega^{2} \sin (\omega t)-m_{p 1} g \\
& m_{p 2} \ddot{x}_{p 2}+c_{p 2} \dot{x}_{p 2}+k_{2}\left(x_{p 2}-x_{p 1}\right)+k_{3}\left(x_{p 2}-x_{b 1}\right)=m_{p 2} e_{2} \omega^{2} \cos (\omega t) \\
& m_{p 2} \ddot{y}_{p 2}+c_{p 2} \dot{y}_{p 2}+k_{2}\left(y_{p 2}-y_{p 1}\right)+k_{3}\left(y_{p 2}-y_{b 1}\right)=m_{p 2} e_{2} \omega^{2} \sin (\omega t)-m_{p 2} g \\
& m_{b 2} \ddot{x}_{b 2}+c_{b 2} \dot{x}_{b 1}+k_{3}\left(x_{b 2}-x_{p 2}\right)+k_{4}\left(x_{b 2}-x_{p 3}\right)=-f_{b 2 x} \\
& m_{b 2} \ddot{y}_{b 2}+c_{b 2} \dot{y}_{b 2}+k_{3}\left(y_{b 2}-y_{p 2}\right)+k_{4}\left(y_{b 2}-y_{p 3}\right)=-f_{b 2 y}-m_{b 2} g \\
& m_{p 3} \ddot{x}_{p 3}+c_{p 3} \dot{x}_{p 3}+k_{4}\left(x_{p 3}-x_{b 2}\right)+k_{5}\left(x_{p 3}-x_{b 2}\right)=m_{p 3} e_{3} \omega^{2} \cos (\omega t) \\
& m_{p 3} \ddot{y}_{p 3}+c_{p 3} \dot{y}_{p 3}+k_{4}\left(y_{p 3}-y_{b 2}\right)+k_{5}\left(y_{p 3}-y_{b 2}\right)=m_{p 3} e_{3} \omega^{2} \sin (\omega t)-m_{p 3} g \\
& m_{b 3} \ddot{x}_{b 3}+c_{b 3} \dot{x}_{b 3}+k_{5}\left(x_{b 3}-x_{p 3}\right)=-f_{b 3 x} \\
& m_{b 3} \ddot{y}_{b 3}+c_{b 3} \dot{y}_{b 3}+k_{5}\left(y_{b 3}-y_{p 3}\right)=-f_{b 3 y}-m_{b 3} g
\end{aligned}
$$

\subsection{Dynamic model of rotor system}

The low pressure compressor rotor of a gas turbine is simplified as a two-span three-support rotor system, which has the characteristic of supporting asymmetry. Front support is a ball bearing, Intermediate support and rear support is a cylindrical rolling bearing. The rotor has concentrated mass at the bearing and turntable with massless elastic shaft between the turntable and bearings. The model ignores torsional and axial vibration of the rotor, only the transverse vibration. Each concentrated mass only considers the degrees of freedom in the $\mathrm{x}$ and $\mathrm{y}$ directions.

From Lagrange equation of the second kind of dissipative system, the dynamic differential equations of low-pressure rotor system of gas turbine can be obtained in formula (2).

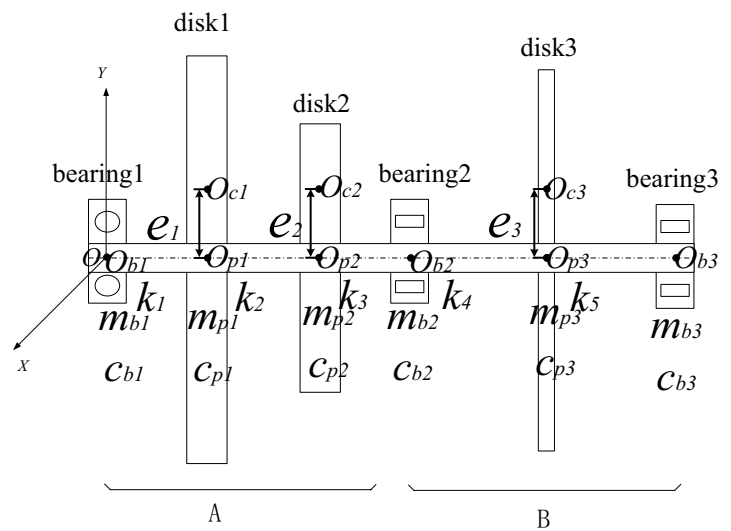

Fig.1 The dynamics model of a low-pressure rotor system for a marine gas turbine

\section{The influence of bearing radial clearance on the nonlinear dynamics of the system}

As the radial clearance of the rear bearing changes, the bifurcation diagram of the disc 2 horizontal displacement Xp2 is shown in Fig.2. It can be found that the nonlinear characteristics of disc 2 changes. The Poincare section diagram is shown in Fig. 3 with the radial clearance of $2 \mu \mathrm{m}$ $20 \mu \mathrm{m}$ and $28 \mu \mathrm{m}$. The radial clearance of $2 \mu \mathrm{m}$, the Poincare section diagram is only an isolated points. It fully illustrates the disc 2 has a single periodic motion. When the radial clearance of the rear bearing is $20 \mu \mathrm{m}$, there are two isolated points in the Poincare section diagram, indicating that the disc 2 is in cycle two motion and has been in cycle two motion for a long time. The disk 2 enters the period two movement through the period-doubling bifurcation pathway. When the radial clearance of the rear bearing is $28 \mu \mathrm{m}$, the Poincare section diagram is a closed circle, indicating that the disc 2 is in a quasi-periodic motion state.

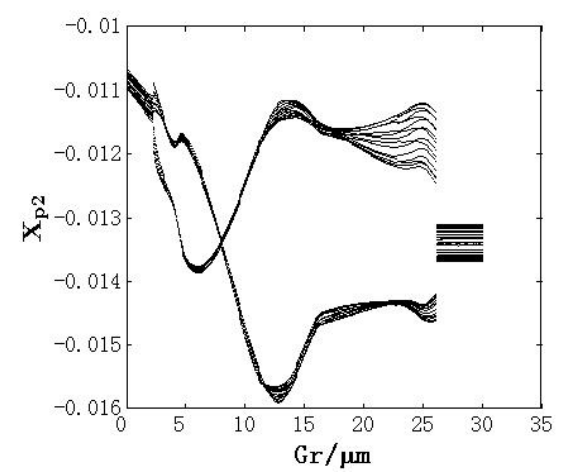

Fig.2 The bifurcation diagram of Xp2 with the change of the radial clearance of the rear bearing 

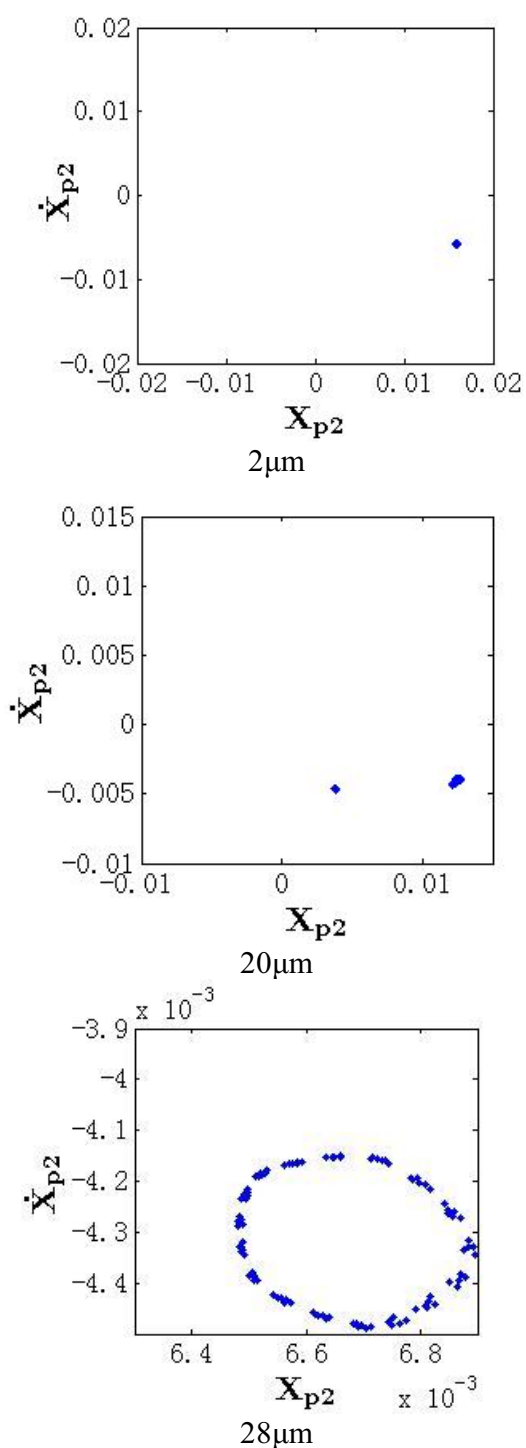

Fig.3 The Poincare section diagram of the rear bearing with the different radial clearance

As the radial clearance of the three bearings changes, the bifurcation diagram of the disc 2 horizontal displacement Xp2 is shown in Fig.4.As the radial clearance of the bearing changes, it can be seen from the figure that the nonlinear characteristics of the disc 2 have complex changes. With different radial clearances, The Poincare section diagram of Xp2 is shown in Fig.5. When the radial clearance is $5 \mu \mathrm{m}$, there is only one isolated point on the Poincare section diagram. When the radial clearance is $8 \mu \mathrm{m}$, there are only two isolated points on the Poincare section diagram. When the radial clearance is $20 \mu \mathrm{m}$, the Poincare section diagram shows four isolated points. When the radial clearance is $28 \mu \mathrm{m}$, the Poincare section diagram is again two isolated points. It shows that with the change of radial clearance, the disc 2 has a bifurcation process of single cycle, cycle two, cycle four and cycle two in sequence. It is found that the nonlinear characteristic of the system varies with the bearing radial clearance.

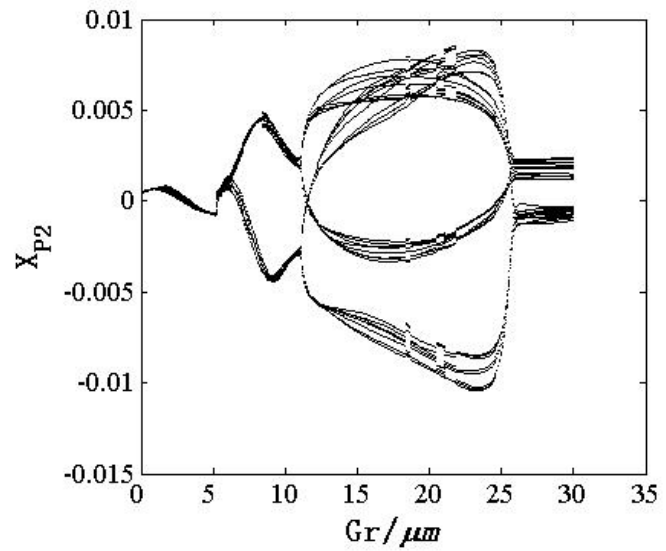

Fig.4 The bifurcation diagram of Xp2 with the change of the three radial clearances
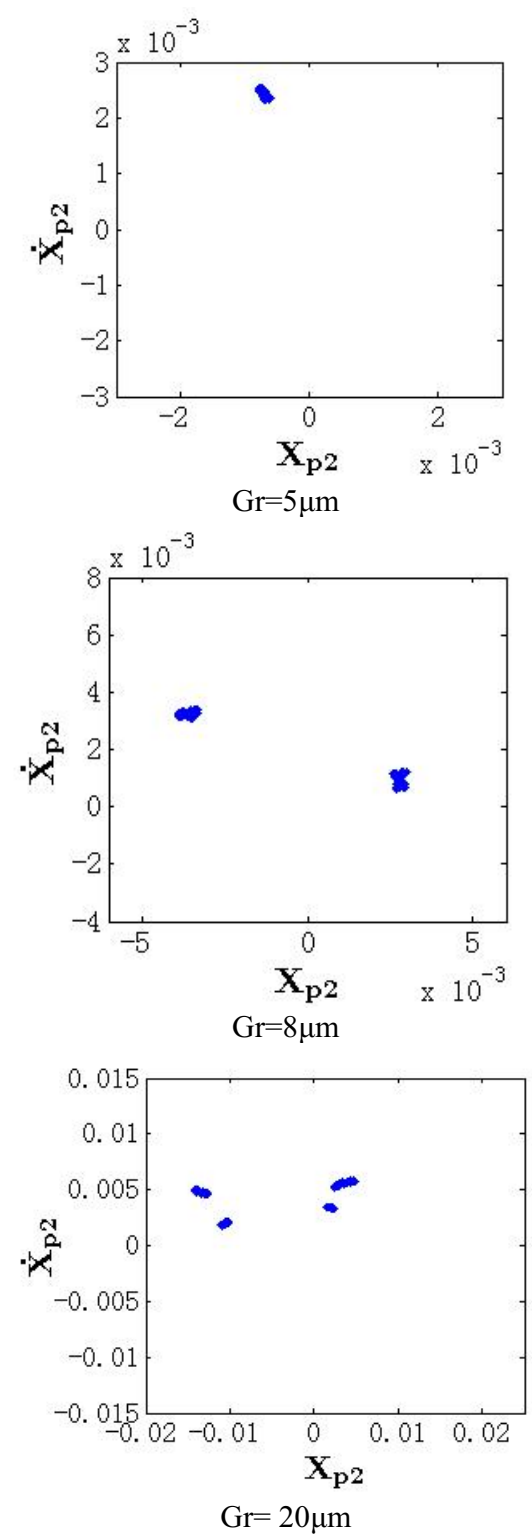


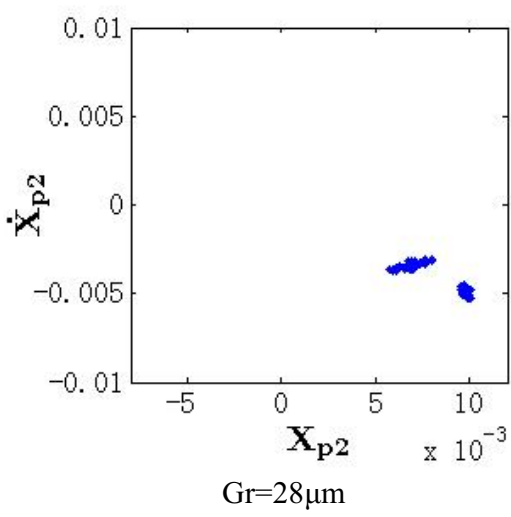

Fig.5 The Poincare section diagram of $\mathrm{X}_{\mathrm{p} 2}$ with different radial clearances

\section{Conclusion}

This article takes a gas turbine low pressure rotor system as the research object, and establishes the double spans three supports plate rolling bearing rotor system dynamics model. The influence of bearing radial clearance on the nonlinear dynamic characteristics of the rotor system is studied. The results show:

As the radial clearance of the rear bearing increases, the rotor system performs single-cycle, two-cycle and quasi-cycle motion. When the radial clearances of the three bearings change at the same time, the system enters into a multi-period movement through a period-doubling bifurcation approach. When the radial clearance exceeds a certain range, because the radial clearance is too large, the system performs a cycle two movement.

\section{Reference}

1. Tiwari M, Gupta K, Prakash O. Effect of radial internal clearance of a ball bearing on the dynamics of a balanced horizontal rotor. Journal of Sound and Vibration, 238(5): 723-756, (2000).

2. Mevel B, Guyader J L. Routes to chaos in ball bearings. Journal of Sound and Vibration, 162(3): 471-487 (1993).

3. CHEN Guo, Nonlinear Dynamic Response Analysis of an Unbalanced Rotor Supported on Ball Bearing. China Mechanical Engineering, 18(23): 2773-2778 (2007).

4. H. Bao-cai, T. Liu-ding, D. Si-er. Nonlinear Dynamics Analysis of the Rotor-rolling Bearing System. Noise and Vibration Control, 4: 20-23 (2008).

5. Y. Ru, Z. Ling-yan, W. San-min. Analysis of the Nonlinear Dynamic Behaviors of a Rolling BearingRotor System. Mechanical Science and Technology, 23(10): 1175-1233 (2004).

6. L. Ming-xuan, Y. Hui-qun, C. Ying-ying. Dynamic characteristics of a ball bearing-offset disk rotor system with whirling-swing coupling. Journal of
Vibration and Shock, 33(12): 36-41 (2014).

7. W. Mei-ling, H. Qin-kai. Research on the effect of offset disc on dynamic characteristics of rotor system . Journal of Dynamics and Control, 9(03): 238-242 (2011).

8. Z. Chun-jin, R. Yong-sheng, T. Ji-shuang. Study on Characteristics of Lateral Nonlinear Vibration in Hollow Shaft Offset Disk Rotor System. Machinery Design \& Manufacture, 9: 54-59 (2017). 